\title{
Vocal stereotypes
}

Melanie Weirich

Centre for General Linguistics (ZAS), Germany

https://doi.org/10.36505/ExLing-2008/02/0058/000117

\begin{abstract}
German speakers receive different ratings in their perceived vocal attractiveness and personality characteristics. An experiment was conducted to evaluate the perceived personality attributions of 32 German listeners and find acoustic cues that correlate to these attributions. The attributed opposition pairs on which the speakers were judged were reduced by a cluster analysis to two factors: dominance (e.g.

"confident", "competent") and benevolence (e.g. "sensitive", "helpful"). The acoustic investigation of the voices of 4 male speakers revealed the impact of several acoustic parameters on the ratings. Among others, the harmonics-tonoise ratio (HNR) and breathy vocal onsets were most important for high ratings on benevolence. High ratings on dominance showed strong correlations to low mean F0 and strong glottal impulses.
\end{abstract}

Key words: vocal stereotypes, vocal attractiveness, personality attributions, dominance, benevolence

\section{Introduction}

For more than 50 years, studies on the attribution of personality characteristics to voice quality descriptions have been conducted (Allport and Cantril 1934, Brown 1982, Zuckerman and Driver 1989, Sendlmeier and Siegmund 2005). While these attributions have been relatively consistent between listeners who had to judge different voices, the reason for this consistency has remained somewhat unclear.

Several of these studies found correlations between subjective evaluations of a voice (e.g. shrillness, loudness, throatiness) and perceived vocal attractiveness. However, the correlations to objective acoustical measures were rather low (Zuckerman and Miyake 1993) or contradictory (e.g. influence of F0 excursions on the factor competence by Brown (1982) and Gélinas-Chebat (2003)). Judgements of several personality factors were matched with different voice parameters. A high speaking rate for example showed a positive effect on the factors competence, activity and attractiveness (Brown 1982, Gélinas-Chebat 2003, Sendlmeier 2005) but a negative effect on benevolence (Sendlmeier 2005).

Thus, the aim of this study is to investigate "vocal stereotypes", i.e. consistent personality attributions and vocal attractiveness ratings of several speakers by different listeners. In addition to that, we will discuss auditory and acoustic correlates to the subjective judgements of the raters.

ExLing 2008: Proceedings of 2nd Tutorial and Research Workshop on Experimental Linguistics, 25-27 August 2008, Athens, Greece 


\section{Method}

We recorded 25 male native speakers of German reading a passage of "The little Prince" by Antoine de Saint-Exupéry. 32 male and female listeners rated each speaker on 15 attribute opposition pairs such as extroverted introverted, competent - incompetent, honest - dishonest on a scale from 17. This method called "semantic differential" extends back to Osgood, Suci and Tannenbaum (1957). In total, 12.000 judgements were elicited (25 speakers x 15 attribute-pairs x 32 listeners).

A cluster analysis was performed on the rating data, reducing the dimensions on which speakers were judged (attribute opposition pairs) to two factors. Orientated on earlier literature we named the factors dominance ("confident", "strong", "competent", etc.) and benevolence ("sensitive", "helpful", "warm", etc.). This finding is consistent with results presented in recent studies (Sendlmeier and Siegmund 2005, Zuckerman and Driver 1989).

This study extends previous work by acoustically investigating the voices of 4 selected speakers that have received rather unambiguous ratings in order to find objective acoustic cues correlated to the consistent attributions of different listeners: The speakers were either high or low on both factor values, or high on one but low on the other.

Mean F0 and formants were measured but special attention has been given to previously rather neglected acoustic measures such as "harmonicsto-noise ratio" (HNR), "Relative Average Perturbation" (RAP) for jitter, and "Amplitude Perturbation Quality" (APQ) for shimmer. RAP describes micro-fluctuations in the mean F0 and reflects the difference between the calculated mean value of three neighboured oscillations and the actual value. Shimmer describes micro-fluctuations in the sound's intensity. Other parameters (breathiness, sonority, harshness) were auditory judged based on acoustic evidence such as VOT, periodicity, harmonics, glottal impulses and vocal onsets (VRT).

\section{Results and discussion}

The speakers were judged significantly different in their vocal attractiveness and personality attributions based on their voices. The high interrater reliabilities show the congruency of the ratings: Cronbach-alpha $=0.97$ (dominance), 0.94 (benevolence) and 0.95 (attractive voice).

\section{The attractive voice}

Our results confirm the findings of Zuckermann and Driver (1989) that listeners judge speakers to be different with regard to vocal attractiveness. In addition to that, the data shows, that the correlation between perceived vocal 
attractiveness and the attributed personality factors dominance and benevolence differ in their strength: The association between attractive voice to dominance was stronger than to benevolence, cp. $\mathrm{r}=0.82$ vs. $\mathrm{r}=0.68$ (Pearson correlation, $\mathrm{p}<.01$, two-sided)

\section{The personality factors benevolence and dominance}

High jitter values correlate with low ratings of benevolence, whereas high shimmer values which are associated with breathiness have a positive effect to benevolence scores. Further, soft and breathy vocal onsets and high values for HNR showed a strongly positive effect to the judgement of benevolence.

Disturbed periodicity and harshness affect both factors negatively, corresponding to results from Teshigawara (2003) and Laver (1994). The correlation of high ratings on dominance and low mean F0 and laryngealisation could also be confirmed (Laver, 1994, Zuckerman and Miyake, 1993). Furthermore, correlations between the attribution of dominance and the existence of numerous harmonics, strong glottal impulses and several intense formants were found. These observations could refer to the connection of spectral tilt of a voice to the attribution of dominance.

Table 1 shows the impact of spectral parameters on the ratings of 4 speakers. Measured mean values from Yumoto, Gould and Baer (1982) for HNR (11.9 dB), from Walton and Orlikoff (1994) for RAP (0.28\%) and from Davis (1979) for APQ5 (5.97 \%) can be used as reference.

Table 1. Measurements of Jitter, Shimmer, HNR and mean F0 of 4 speakers scoring high or low on dominance/benevolence and a combination thereof.

\begin{tabular}{|l|l|l|l|l|l|l|}
\hline speaker & dom. & ben. & HNR (dB) & RAP (\%) & APQ5 (\%) & mean F0 (Hz) \\
\hline 1 & high & low & 8.30 & 0.94 & 4.22 & 99.28 \\
\hline 2 & low & low & 6.95 & 1.34 & 5.24 & 129.30 \\
\hline 3 & low & high & 10.80 & 0.37 & 6.88 & 133.00 \\
\hline 4 & high & high & 11.60 & 0.34 & 5.75 & 89.40 \\
\hline
\end{tabular}

Several acoustic patterns of the voice could be linked positively or negatively to both factors of personality. Especially features of laryngeal settings and here above all breathiness seem to have the greatest influence to positive attributions in regard to the factor benevolence. High scores in the factor dominance were more closely related to low mean F0 with laryngeal voice, glottal and pharyngeal laxness and a high sonority reflected through the existence of numerous harmonics and strong glottal impulses. Laryngeal and supra laryngeal settings but also the speaking style played a role. 


\section{Conclusion}

The study confirmed the existence of vocal stereotypes for male speakers of German and explored various spectral parameters associated with the raters' conforming judgements regarding perceived personality factors and voice attractiveness. Additionally, a difference in the judgements of the listeners depending on gender was found: Female listeners rated the male voices significantly more positive than their male colleagues. That could be interpreted in terms of competition within gender and should be investigated more intensely in further research. These results, identifying the acoustic resources employed in the performance of dominance and possibly gender in general, are of great interest to sociolinguists and sociophoneticians.

\section{References}

Allport, G.W. and Cantril, H. 1934. Judging Personality from voice. Journal of Social Psychology 5, 37-55.

Brown, B.L. 1982. Experimentelle Untersuchungen zur Personenwahrnehmung aufgrund vokaler Hinweisreize. In Scherer, K. (ed.), Vokale Kommunikation. Weinheim und Basel, Beltz Verlag, 211-227.

Davis, S.B. 1979. Acoustic characteristics of normal and pathological voices. In Lass, N.J. (ed.), Speech and language: Basic advances in research and practice. New York, Academic Press, 271-335.

de Saint-Exupéry, A. (2000). Der kleine Prinz. Karl Rauch-Verlag.

Gélinas-Chebat, C., Chebat, J.-C. and Boivin, R. 2003. Voice and Information Processing. Proc. of the 15th Int. Congress of Phonetic Sciences, 667-670, Barcelona, Spain.

Laver, J. 1994. Principles of phonetics. Cambridge, University Press.

Osgood, C.E., Suci, G.J. and Tannenbaum, P.H. 1957. The measurement of meaning. University of Illinois.

Sendlmeier, W. and Siegmund, J. 2005. DeutschlandRadio Berlin vs. Radio NRJ Berlin - Ein Vergleich der Sprechstile. In Sendlmeier, W. (ed.) 2005, Sprechwirkung. Sprechstile in Funk und Fernsehen, 121-149. Berlin, Logos Verlag.

Teshigawara, M. 2003. Voices in Japanese Animation: How People Perceive Voices of Good Guys and Bad Guys. Proc. of the 15th Int. Congress of Phonetic Sciences, 2413-2416, Barcelona, Spain.

Walton, J.H. and Orlikoff, R.F. 1994. Speaker race identification from acoustic cues in the vocal signal. Journal of Speech and Hearing Research 37, 738-745.

Yumoto, E., Gould, W.J. And Baer, T. 1982. Harmonics-to-noise ratio as an index of the degree of hoarseness. Journal of the Acoustical Society of America 71, 1544-1550.

Zuckerman, M. and Driver, R.E. 1989. What sounds beautiful is good: The vocal attractiveness stereotype. Journal of Nonverbal Behavior 13 (2), 67-82.

Zuckerman, M. and Miyake, K. 1993. The attractive voice: What makes it so? Journal of Nonverbal Behavior 17, 119-135. 